\title{
Effects of Sleep Quality on the Academic Performance of Undergraduate Medical Students
}

\author{
Sepehr Rasekhi,, ${ }^{1,}$ Fazilat Pour Ashouri, ${ }^{1}$ and Afsoon Pirouzan ${ }^{2}$ \\ ${ }^{1}$ Student Research Committee, Hormozgan University of Medical Sciences, Bandar Abbas, IR Iran \\ ${ }^{2}$ Department of English language, Faculty of Medicine, Hormozgan University of Medical Sciences, Bandar Abbas, IR Iran \\ "Corresponding author: Sepehr Rasekhi, Student Research Committee, Hormozgan University of Medical Sciences, Bandar Abbas, IR Iran. Tel: +98-9363945856, E-mail: \\ flosep538@gmail.com
}

Received 2015 July 19; Revised 2015 December 04; Accepted 2016 January 10.

\begin{abstract}
Background: Medical students are exposed to a significant level of pressure because of their academic demands. Thus, they are at increased risk for sleep disorders.

Objectives: This study was conducted to examine the prevalence of sleep disturbance among medical students and investigate any relationship between sleep disorder and academic performance.

Materials and Methods: This work is a cross-sectional questionnaire-based study. Participants of this study consisted of first-, second-, and third-year medical students. The Pittsburgh sleep quality index (PSQI) was adopted to identify sleep disorder, and the grade point average of the students was recorded for academic performance.

Results: A total of 177 respondents, with a response rate of 55\%, were obtained. According to the PSQI score, $36.6 \%$ of participants were considered to have abnormal sleep habits, with a statistically significant increase in female students $(\mathrm{P}<0.05)$. Abnormal PSQI scores were associated with lower academic achievement $(\mathrm{P}<0.05)$. Marital status, habitat, smoking and physical activity were also associated with PSQI scores.

Conclusions: A high prevalence of sleep disorder was found in this population, specifically among female students. Analysis of the relationship between sleep disorder and academic performance indicates a significant relationship of PSQI scores with marital status, habitat, smoking, physical activity, and academic performance.
\end{abstract}

Keywords: Academic Performance, Medical Students, Pittsburgh Sleep Quality Index, Sleep Quality

\section{Background}

Sleep disturbance is a psychiatric disorder. It is related to one of our biological rhythms called the circadian timing system, which is influenced by factors such as physiological function, school and work schedules, and various medical conditions of the body including genetic differences $(1,2)$. Many factors determine sleep quality, and some of the important ones are age, gender, habitat, body mass index (BMI), physical activity or sports, smoking, and marital status (3).

The human body normally requires seven hours of night sleep and eight to nine hours of daily sleep. Sleepiness is inversely proportional to hours of sleep, and it may have a substantial adverse effect on general health and quality of life. Conversely, adequate sleep can lead to a better quality of life, physical and social health, life satisfaction, performance, and longevity $(4,5)$.

The medical student population is one of the populations that appear to be at increased risk for sleep deprivation $(6,7)$ because they need to be awake to do their duty in the hospital or are under constant stress because of their examinations. The prevalence of sleep disorders in the general population has been estimated to be $15 \%-35 \%$ (8), and in medical students it was evaluated at about $30 \%$ (9). Recent studies have demonstrated that the sleep-wake cycle of medical students is characterized by insufficient sleep duration, delayed sleep onset, and occurrence of napping episodes during the day $(10,11)$, which has been found to affect cognitive function in medical students (12). Moreover, multiple studies have indicated a high correlation between sleep duration and performance in some activities and in subjective alertness $(13,14)$. Medical students require cognition and alertness abilities that are impeded by sleep disorders (12).

Many studies have demonstrated a high level of psychological distress, anxiety, and depression in medical students in different countries (15). Another study showed that a relationship exists between sleep disturbance and psychiatric disorders, especially depression and anxiety, among medical students. The manifestations of sleep disorders could precede or be associated with psychiatric ill- 
nesses (16). Many studies have been conducted among medical students supporting the finding that low sleep quality could affect the academic and clinical performance of medical students because of its compatibility with cognition ability (17-19). However, some studies have denied any relation between sleep quality and performance among residents (20).

\section{Objectives}

Despite a high number of studies on medical students, few studies have investigated the sleep habits and patterns of undergraduate medical students. Based on the significance of sleep quality on academic performance, especially among medical students, and because of the lack of studies among undergraduate medical students, this research was conducted to determine the effect of sleep quality on the scores of undergraduate medical students of Bandar Abbas Medical School in Iran in 2015.

\section{Materials and Methods}

A cross-sectional study was conducted in 2015 in the Bandar Abbas Medical School in Iran among undergraduate medical students. A total of 240 first-, second-, and third-year medical students participated in this study. Students at these academic levels do not have night calls or shift rotations. Among them, 135 were female and 105 were male. The Pittsburgh sleep quality index (PSQI), a self-rated questionnaire that assesses sleep quality over a time interval of one month, was adopted in the survey. Seven properties of sleep were evaluated by this questionnaire:

1. Sleep quality of the individual

2. Time it takes for an individual to sleep

3. Duration of sleep

4. Sleep efficiency

5. Bedtime problems

6. Use of sleeping medication

7. Impairment in daily functioning

The scores for each question range from 0 to 3 , with 0 indicating the highest sleep quality and 3 indicating the lowest one. The seven component scores are then added to yield a global PSQI score in the range of 0 to 21; the higher the score is, the worse the sleep quality. A global score equal or greater than 5 indicates poor sleep quality in the past month. PSQI was translated for Iran by Yazdi et al. (21). The high values of validity and reliability (94\% and $72 \%$, respectively) and the Cronbach's alpha coefficient of 0.77 for this questionnaire were assessed by Farrahi Moghaddam et al. (22). All the participants were informed about the targets of the research, the methods of the study, and how to fill the questionnaires. All procedures were performed only with the consent of the participants, and all information was used solely for this research. Those who did not give their consent to participate were excluded. The subjects were followed-up for a month, their academic scores were recorded, and finally their average scores (GPA) were evaluated for that month. These average scores were considered as their academic performance in the present study, and obtaining these scores is a known method to define academic performance in sleep research (23). School performance was stratified as high (3.5 or higher), good (3 - 3.49), normal (2 - 2.99), and low (less than 2). Afterwards, a complete history was taken from the subjects in relation to their academic year, sleep hours, midday nap, and major causes of sleep disturbance mentioned in the literature: age, gender, habitat, BMI, physical activity, smoking, and marital status. A screening for chronic medical or psychiatric illnesses was performed during the interview. Students with known chronic medical illnesses or those who were taking drugs that cause sleepiness were excluded from the study. Then, the questionnaires were distributed among the participants. After completion, the questionnaires were collected from the subjects, and the incomplete ones (e.g., an unanswered item or an ambiguous answer) were removed from the study. SPSS V.19 program was used to enter and analyze the data. T-test was then used for processing quantitative information and chisquare test for the qualitative information. The effects of sleep quality on the academic performance of medical students were determined by multivariate analysis. A twosided $\alpha=0.05$ was considered statistically significant.

\section{Results}

A total of 177 responses were obtained from the 240 students, thus giving a response rate of $74 \%$. Among all the participants, $66.66 \%$ were considered poor sleepers. The mean age of the participants, which ranged from 17 to 31 years, was $20.99 \pm 2.14$. Among this population, 83 (46.9\%) were male and 94 (53.1\%) were female. When school performance was stratified into high (3.5 or higher), good (3 - 3.49), normal (2 - 2.99), and low (less than 2), 26 students (14.7\%) had "high" scores, 78 students (44.06\%) had "good" scores, 65 students (36.72\%) had "normal" scores, and 8 students (4.52\%) had "low" scores. The students were distributed almost equally among the three academic years. Daily sleeping hours of 4 - 6 hours were reported by 110 (62.1\%) of the participants and 7 - 10 hours by 45 (25.4\%). A small numbers of students slept less than 4 hours or more than 10 hours (12.5\%). Among the students, 59 (33.34\%) had normal PSQI scores and 118 (66.66\%) had abnormal PSQI 
scores. Table 1 presents the complete demographic characteristics and other study variables.

Table 2 presents the analysis of the study variables with PSQI scores. A multivariate analysis of sleep disturbance and academic performance with full adjustment of the study variables revealed a significant relationship between sleep disturbance and academic performance. Students with high grades had significantly better sleep quality than those with low grade, who went to bed sooner, who fell asleep later, who had shorter sleep duration, with less habitual sleep efficiency, with more sleep disturbances, and with more daytime dysfunction. Regarding sex differences, girls had poorer sleep quality than boys. Aside from sex and academic performance, sleep quality also had a significant relationship with marital status, habitat, smoking, and physical activity. The prevalence of sleep disorders was higher in smokers and those who lived in dorms. Sleep quality was significantly higher among athletes and married participants.

\section{Discussion}

To our knowledge, this local study is the first to investigate the relationship between sleep deprivation of undergraduate medical students and their academic achievements. The current study demonstrates that optimized sleep patterns may improve academic performance and learning ability; conversely, poor sleep quality is associated with low academic performance and learning ability. These findings agree with those of a study conducted on medical students demonstrating that $38.9 \%$ of students had poor sleep quality according to the PSQI (24). In the present study, sleep disturbance is very com-mon among medical students, as reported by $66.66 \%$ of the respondents. This finding is relatively close to that of another study in Iran (25). This result illustrates the high frequency of sleep disorders and the low quality of sleep among Iranian students. However, studies are lacking about the effect of sleep quality on scores of undergraduate medical students, and thus we compared our study with other studies on students or higher-level medical students. One of the first studies that examined the relationship between sleep patterns and academic performance of medical students was that of Johns et al. (19), which was followed by more studies. These studies have shown that sleep disturbances can affect learning ability and memory, which are factors that determine the academic performance of students (26). In a study based on answers to self-assessment surveys among students in the last two years of medical school and residents, Daugherty and Baldwin revealed that too little sleep is debilitating and harmful to the learning process (27). Other studies have also revealed that sleep deprivation is a common finding in student academic life and that the prevalence of excessive daytime sleepiness among the medical students on the Epworth sleepiness scale was higher than normal (28, 29). Richardson et al. found that sleep in a hospital does not restore chronic sleep deprivation (30). Another objective evaluation conducted on medical professionals indicated a reduced capacity to perform intellectually demanding or non-stimulating tasks (31). In a similar study, Ficke et al. analyzed the academic performance of medical students who were divided into two groups: snorers and non-snorers. The results of their study showed that snorers only achieved average scores of $65 \%$ on their finals, whereas non-snorers achieved average scores of $71 \%$, which was significantly higher (32). Nonetheless, the consequences of sleep deprivation among doctors and medical students still constitute a point of discussion among researchers. Deaconson et al. and Browne et al. found no significant changes in the capacity to learn cognition, and thus they concluded no negative effects on the performance of residents and medical students $(20,33)$. In the current study, several factors such as gender, marital status, habitat, smoking, and physical activity were associated with sleeping disorder among medical students. Consistent with our results, Nojomi et al. demonstrated a significant association of age, gender, living conditions, doing exercise, and workload with sleep disturbance among medical students and residents (34). These risk factors, aside from socioeconomic status, life habits, and psychological factors, were also demonstrated for sleep disorders in other studies $(7,29)$. The results of the present study revealed that female medical students have a higher prevalence of sleep disorder than males, consistent with the study of Keshavarz Akhlaghi and Ghalebandi conducted among pre-university students in Karaj, Iran (25). By contrast, Ghanizadeh et al. revealed that the mean duration of night sleep in high school students in Iran is not different between genders. Therefore, some special characteristics of various populations may be a determinant of this difference (35). In a recent study of 238 adolescents, a significant correlation was found between school performance and snoring. Snoring on a nightly basis was found to be significantly common among students with GPA of less than 3.5. The sleep variables significantly affecting school performance in this study were mainly associated with daytime sleepi-ness (difficulty concentrating and falling asleep in class). The results also determined that household income is a significant variable affecting the reported GPA(36). Our study provides further evidence supporting the contention that sleep disturbance occurs at high frequencies among medical students and significantly affects their performance as measured by their GPA. 
Table 1. Demographic Characteristics and Other Variables of the Study Population

\begin{tabular}{|c|c|}
\hline Variables & No. $(\%)$ \\
\hline \multicolumn{2}{|l|}{ Sex } \\
\hline Male & $83(46.9)$ \\
\hline Female & $94(53.1)$ \\
\hline \multicolumn{2}{|l|}{ Marital status } \\
\hline Single & $131(74)$ \\
\hline Married & $46(26)$ \\
\hline \multicolumn{2}{|l|}{ Academic year } \\
\hline First & $72(40.6)$ \\
\hline Second & $61(34.5)$ \\
\hline Third & $44(24.9)$ \\
\hline \multicolumn{2}{|l|}{ Habitat } \\
\hline Dorm & $114(64.4)$ \\
\hline Home & $63(35.6)$ \\
\hline \multicolumn{2}{|l|}{ BMI } \\
\hline$<18.5$ & $36(20.34)$ \\
\hline $18.5-24.9$ & $79(45.3)$ \\
\hline $25-29.9$ & $44(24.86)$ \\
\hline$>30$ & $18(9.5)$ \\
\hline \multicolumn{2}{|l|}{ Midday nap } \\
\hline Yes & $105(59.3)$ \\
\hline No & $72(40.7)$ \\
\hline \multicolumn{2}{|l|}{ Sleep hours, $\mathbf{h}$} \\
\hline $4-6$ & $110(62.1)$ \\
\hline $7-10$ & $45(25.4)$ \\
\hline Others & $22(12.5)$ \\
\hline \multicolumn{2}{|l|}{ Smoking } \\
\hline Yes & $16(9)$ \\
\hline No & $161(91)$ \\
\hline \multicolumn{2}{|l|}{ Physical activity } \\
\hline $3 \leq$ sessions a week & $18(10.16)$ \\
\hline Twice a week & $34(19.2)$ \\
\hline Once a week & $27(15.25)$ \\
\hline None & $98(55.39)$ \\
\hline \multicolumn{2}{|l|}{ Academic scores (GPA) } \\
\hline High (3.5 or higher) & $26(14.7)$ \\
\hline Good (3-3.49) & $78(44.06)$ \\
\hline $\operatorname{Normal}(2-2.99)$ & $65(36.72)$ \\
\hline Low (less than 2) & $8(4.52)$ \\
\hline \multicolumn{2}{|l|}{ PSQI scores } \\
\hline $\operatorname{Normal}(<5)$ & $59(33.34)$ \\
\hline $\operatorname{Abnormal}(5 \leq)$ & $118(66.66)$ \\
\hline
\end{tabular}


Table 2. Analysis of PSQI Scores With Other Study Variables ${ }^{\mathrm{a}}$

\begin{tabular}{|c|c|c|c|c|}
\hline Variables & $\mathrm{PSQI}<\mathbf{5}$ & PSQI $\geq 5$ & Total & P Value \\
\hline Sex & & & & $<0.05$ \\
\hline Male & $38(45.8)$ & $45(54.2)$ & $83(100)$ & \\
\hline Female & $21(22.3)$ & $73(77.7)$ & $94(100)$ & \\
\hline Marital status & & & & $<0.05$ \\
\hline Married & $33(71.7)$ & $13(28.3)$ & $46(100)$ & \\
\hline Academic year & & & & $>0.05$ \\
\hline First & $23(32)$ & $49(68)$ & $72(100)$ & \\
\hline Second & $24(39)$ & $37(61)$ & $61(100)$ & \\
\hline Third & $12(27)$ & $32(73)$ & $44(100)$ & \\
\hline Dorm & $24(21)$ & $90(79)$ & $114(100)$ & \\
\hline Home & $35(55.56)$ & $28(44.44)$ & $63(100)$ & \\
\hline BMI & & & & $>0.05$ \\
\hline$<18.5$ & $13(36)$ & $23(64)$ & $36(100)$ & \\
\hline $18.5-24.9$ & $21(26.6)$ & $58(73.4)$ & $79(100)$ & \\
\hline $25-29.9$ & $16(36.4)$ & $28(63.6)$ & $44(100)$ & \\
\hline$>30$ & $9(50)$ & $9(50)$ & $18(100)$ & \\
\hline Midday nap & & & & $>0.05$ \\
\hline Yes & $32(30.5)$ & $73(69.5)$ & $105(100)$ & \\
\hline No & $27(37.5)$ & $45(62.5)$ & $72(100)$ & \\
\hline $4-6$ & $23(21)$ & $87(79)$ & $110(100)$ & \\
\hline $7-10$ & $17(38)$ & $28(62)$ & $45(100)$ & \\
\hline Others & $9(41)$ & $13(59)$ & $22(100)$ & \\
\hline Smoking & & & & $<0.05$ \\
\hline Yes & $14(87.5)$ & $2(13.5)$ & $16(100)$ & \\
\hline No & $45(28)$ & $116(72)$ & $16(100)$ & \\
\hline Physical activity & & & & $<0.05$ \\
\hline $3 \leq$ sessions a week & $13(72)$ & $5(28)$ & $18(100)$ & \\
\hline Twice a week & $15(44)$ & $19(56)$ & $34(100)$ & \\
\hline Once a week & $11(41)$ & $16(59)$ & $27(100)$ & \\
\hline None & $20(20.4)$ & $78(79.6)$ & $98(100)$ & \\
\hline Academic scores & & & & $<0.05$ \\
\hline High (3.5 or higher) & $21(80.7)$ & $5(19.3 \%)$ & $26(100)$ & \\
\hline Good (3-3.49) & $27(34.6)$ & $51(65.4)$ & $78(100)$ & \\
\hline Normal (2 - 2.99) & $10(15.4)$ & $55(84.6)$ & $65(100)$ & \\
\hline Low (less than 2) & $1(12.5)$ & $7(87.5)$ & $8(100)$ & \\
\hline
\end{tabular}

${ }^{\mathrm{a}}$ Values are expressed as No. (\%). 
Poor sleep limits the learning of medical students, and setting a proper sleep schedule is an effective way to the boost scores of medical students. As in most observational studies on sleep, sleep disorders are based only on subjective assessment by the respondent. False information may be provided by students answering the questionnaires, and students may also be unable to understand or may misinterpret the questions. Moreover, the respondents may not have considered a few nights of sleep difficulty due to stress to be equivalent to insomnia or to a persistent sleep disturbance. This study also suggests that socioeconomic variables, particularly household income, should be assessed in further epidemiological studies on sleep disturbance and academic performance of medical students.

\subsection{Conclusions}

This study reveals a high prevalence of sleep disorder among medical students. The analysis of the relationship between sleep disorder and academic achievement shows a significant relationship. Therefore, undergraduate medical students should be educated about the importance of adequate sleep to their academic performance. Female students have more sleep disorders than do male students. Marital status, habitat, smoking, and physical activity also have a significant relationship with sleep quality. These factors may affect students' academic performance, and we recommend further investigation to clarify this finding.

\section{Footnote}

Authors' Contribution: Sepehr Rasekhi the guarantor of the study, developed the original idea and the protocol, abstracted, and wrote the manuscript. Fazilat Pour Ashouri and Afsoon Pirouzan contributed to the development of the protocol, analyzed data, and prepared the manuscript.

\section{References}

1. Heath AC, Kendler KS, Eaves LJ, Martin NG. Evidence for genetic influences on sleep disturbance and sleep pattern in twins. Sleep. 1990;13(4):318-35. [PubMed: 2267475].

2. Davidson JR, MacLean AW, Brundage MD, Schulze K. Sleep disturbance in cancer patients. Social Sci Med. 2002;54(9):1309-21.

3. Haseli-Mashhadi N, Dadd T, Pan A, Yu Z, Lin X, Franco OH. Sleep quality in middle-aged and elderly Chinese: distribution, associated factors and associations with cardio-metabolic risk factors. BMC Public Health. 2009;9:130. doi:10.1186/1471-2458-9-130. [PubMed: 19426521].

4. Durmer JS, Dinges DF. Neurocognitive consequences of sleep deprivation. Semin Neurol. 2005;25(1):117-29. doi: 10.1055/s-2005-867080. [PubMed: 15798944].

5. Kripke DF, Garfinkel L, Wingard DL, Klauber MR, Marler MR. Mortality associated with sleep duration and insomnia. Arch Gen Psychiatry. 2002;59(2):131-6. [PubMed: 11825133].

6. Veldi M, Aluoja A, Vasar V. Sleep quality and more common sleeprelated problems in medical students. Sleep Med. 2005;6(3):269-75. doi: 10.1016/j.sleep.2004.12.003. [PubMed: 15854858].
7. Loayza H, Ponte TS, Carvalho CG, Pedrotti MR, Nunes PV, Souza CM, et al. Association between mental health screening by self-report questionnaire and insomnia in medical students. Arq Neuropsiquiatr. 2001;59(2-A):180-5. [PubMed: 11400021].

8. Ohayon MM, Guilleminault C. Epidemiology of sleep disorders. Sleep: A Comprehensive Handbook. Hoboken, New Jersey: Wiley-Liss; 2006.

9. Foley DJ, Monjan AA, Brown SL, Simonsick EM, Wallace RB, Blazer DG. Sleep complaints among elderly persons: an epidemiologic study of three communities. Sleep. 1995;18(6):425-32. [PubMed: 7481413].

10. Ng EP, Ng DK, Chan CH. Sleep duration, wake/sleep symptoms, and academic performance in Hong Kong Secondary School Children. Sleep Breath. 2009;13(4):357-67. doi: 10.1007/s11325-009-0255-5. [PubMed: 19377905].

11. Sweileh WM, Ali IA, Sawalha AF, Abu-Taha AS, Zyoud SH, Al-Jabi SW. Sleep habits and sleep problems among Palestinian students. Child Adolesc Psychiatry Ment Health. 2011;5(1):25. doi:10.1186/1753-2000-5-25. [PubMed: 21762479].

12. Roth T, Zammit G, Kushida C, Doghramji K, Mathias SD, Wong JM, et al. A new questionnaire to detect sleep disorders. Sleep Med. 2002;3(2):99-108. [PubMed: 14592227].

13. Cronin AJ, Keifer JC, Davies MF, King TS, Bixler EO. Postoperative sleep disturbance: influences of opioids and pain in humans. Sleep. 2001;24(1):39-44. [PubMed: 11204052].

14. Bazil CW. Epilepsy and sleep disturbance. Epilepsy Behav. 2003;4:3945.

15. Eller T, Aluoja A, Vasar V, Veldi M. Symptoms of anxiety and depression in Estonian medical students with sleep problems. Depress Anxiety. 2006;23(4):250-6. doi:10.1002/da.20166. [PubMed:16555263].

16. Rosal MC, Ockene IS, Ockene JK, Barrett SV, Ma Y, Hebert JR. A longitudinal study of students' depression at one medical school. Acad Med. 1997;72(6):542-6. [PubMed: 9200590].

17. Deary IJ, Tait R. Effects of sleep disruption on cognitive performance and mood in medical house officers. Br Med J (Clin Res Ed). 1987;295(6612):1513-6. [PubMed: 3122881].

18. Weinger MB, Ancoli-Israel S. Sleep deprivation and clinical performance. JAMA. 2002;287(8):955-7. [PubMed: 11866625].

19. Johns MW, Dudley HA, Masterton JP. The sleep habits, personality and academic performance of medical students. Med Educ. 1976;10(3):15862. [PubMed: 1268120$]$.

20. Deaconson TF, O'Hair DP, Levy MF, Lee MB, Schueneman AL, Codon RE. Sleep deprivation and resident performance. JAMA. 1988;260(12):17217. [PubMed: 3411755].

21. Yazdi Z, Sadeghniiat-Haghighi K, Zohal MA, Elmizadeh K. Validity and reliability of the Iranian version of the insomnia severity index. Malays J Med Sci. 2012;19(4):31-6. [PubMed: 23613647].

22. Farrahi Moghaddam J, Nakhaee N, Sheibani V, Garrusi B, Amirkafi A. Reliability and validity of the Persian version of the Pittsburgh Sleep Quality Index (PSQI-P). Sleep Breath. 2012;16(1):79-82. doi: 10.1007/s11325-010-0478-5. [PubMed: 21614577].

23. Millman RP, Working Group on Sleepiness in Adolescents/Young A, A. A. P. Committee on Adolescence . Excessive sleepiness in adolescents and young adults: causes, consequences, and treatment strategies. Pediatrics. 2005;115(6):1774-86. doi:10.1542/peds.2005-0772. [PubMed: 15930245].

24. Medeiros ALD, Mendes DBF, Lima PF, Araujo JF. The Relationships between Sleep-Wake Cycle and Academic Performance in Medical Students. Biol Rhythm Res. 2003;32(2):263-70. doi: 10.1076/brhm.32.2.263.1359.

25. Keshavarz Akhlaghi AA, Ghalebandi MF. Sleep quality and its correlation with general health in pre-university students of Karaj, Iran. Iran JPsychiatr Behav Sci. 2009;3(1):44-9.

26. Curcio G, Ferrara M, De Gennaro L. Sleep loss, learning capacity and academic performance. Sleep Med Rev. 2006;10(5):323-37. doi: 10.1016/j.smrv.2005.11.001. [PubMed: 16564189]. 
27. Daugherty SR, Baldwin DJ. Sleep deprivation in senior medical students and first-year residents. Acad Med. 1996;71(1 Suppl):S93-5. [PubMed: 8546796].

28. Rodrigues RND, Viegas CA, Abreu e Silva AA, Tavares P. Daytime sleepiness and academic performance in medical students. Arquivos de neuro-psiquiatria. 2002;60(1):6-11.

29. Abdulghani HM, Alrowais NA, Bin-Saad NS, Al-Subaie NM, Haji AM Alhaqwi AI. Sleep disorder among medical students: relationship to their academic performance. Med Teach. 2012;34 Suppl 1:S37-41. doi: 10.3109/0142159X.2012.656749. [PubMed: 22409189].

30. Richardson GS, Wyatt JK, Sullivan JP, Orav EJ, Ward AE, Wolf MA, et al. Objective assessment of sleep and alertness in medical house staff and the impact of protected time for sleep. Sleep. 1996;19(9):718-26. [PubMed: 9122559].

31. Light AI, Sun JH, McCool C, Thompson L, Heaton S, Bartle EJ. The effects of acute sleep deprivation on level of resident training. Curr Surg. 1989;46(1):29-30. [PubMed: 2721234]
32. Ficke JH, Hahn EG. Are snoring students more likely to fail their exams?. Meeting Abstracts of the American Lung Association. American Thoracic Society International Conference. 1998. pp. 24-9.

33. Browne BJ, Van Susteren T, Onsager DR, Simpson D, Salaymeh B, Condon RE. Influence of sleep deprivation on learning among surgical house staff and medical students. Surgery. 1994;115(5):604-10. [PubMed: 8178259].

34. Nojomi M, Ghalhe Bandi MF, Kaffashi S. Sleep pattern in medical students and residents. Arch Iran Med. 2009;12(6):542-9. [PubMed: 19877745].

35. Ghanizadeh A, Kianpoor M, Rezaei M, Rezaei H, Moini R, Aghakhani $\mathrm{K}$, et al. Sleep patterns and habits in high school students in Iran. Ann Gen Psychiatry. 2008;7:5. doi: 10.1186/1744-859X-7-5. [PubMed: 18339201].

36. Pagel JF, Forister N, Kwiatkowki C. Adolescent sleep disturbance and school performance: the confounding variable of socioeconomics. $J$ Clin Sleep Med. 2007;3(1):19-23. [PubMed: 17557448]. 